\title{
Comparative Host-Pathogen Interaction Analyses of SARS-CoV2 and Aspergillus fumigatus, and Pathogenesis of COVID-19-Associated Aspergillosis
}

\author{
Abdul Arif Khan ${ }^{1}$ [ $\cdot$ Fozia Farooq ${ }^{2} \cdot$ Sudhir K. Jain ${ }^{2} \cdot$ Patrycja Golinska ${ }^{3} \cdot$ Mahendra Rai $^{3,4}$ \\ Received: 23 June 2021 / Accepted: 25 October 2021 / Published online: 4 November 2021 \\ (c) The Author(s), under exclusive licence to Springer Science+Business Media, LLC, part of Springer Nature 2021
}

\begin{abstract}
COVID-19 caused a global catastrophe with a large number of cases making it one of the major pandemics of the human history. The clinical presentations of the disease are continuously challenging healthcare workers with the variation of pandemic waves and viral variants. Recently, SARS-CoV2 patients have shown increased occurrence of invasive pulmonary aspergillosis infection even in the absence of traditional risk factors. The mechanism of COVID-19-associated aspergillosis is not completely understood and therefore, we performed this system biological study in order to identify mechanistic implications of aspergillosis susceptibility in COVID-19 patients and the important targets associated with this disease. We performed host-pathogen interaction (HPI) analysis of SARS-CoV2, and most common COVID-19-associated aspergillosis pathogen, Aspergillus fumigatus, using in silico approaches. The known host-pathogen interactions data of SARS-CoV2 was obtained from BIOGRID database. In addition, A. fumigatus host-pathogen interactions were predicted through homology modeling. The human targets interacting with both pathogens were separately analyzed for their involvement in aspergillosis. The aspergillosis human targets were screened from DisGeNet and GeneCards. The aspergillosis targets involved in both HPI were further analyzed for functional overrepresentation analysis using PANTHER. The results indicate that both pathogens interact with a number of aspergillosis targets and altogether they recruit more aspergillosis targets in host-pathogen interaction than alone. Common aspergillosis targets involved in HPI with both SARS-CoV2 and A. fumigatus can indicate strategies for the management of both conditions by modulating these common disease targets.
\end{abstract}

Keywords Infection $\cdot$ System biology $\cdot$ Coronavirus $\cdot$ Pandemic $\cdot$ Biological network $\cdot$ Host-pathogen interactions

\section{Introduction}

SARS-CoV2 infection is reported to be associated with several co-infections contributing to COVID-19-associated complications and mortality. A number of studies

Abdul Arif Khan

abdularifkhan@gmail.com

1 Division of Microbiology, Indian Council of Medical Research-National AIDS Research Institute, Pune, Maharashtra, India

2 School of Studies in Microbiology, Vikram University, Ujjain, Madhya Pradesh, India

3 Department of Microbiology, Nicolaus Copernicus University, Torun, Poland

4 Department of Biotechnology, Sant Gadge Baba Amravati University, Amravati, Maharashtra, India documented occurrence of invasive pulmonary aspergillosis (IPA) in COVID-19 patients [1-10]. It is reported that diagnosis of IPA is a challenging task which is associated with high morbidity and mortality [11, 12]. Literature survey indicated that COVID-19 patients may develop Aspergillus infection even in the absence of traditional risk factors and its incidence ranges from 19.6 to $33.3 \%$ [12]. It is found that COVID-19 patients can develop aspergillosis even after testing negative for SARS-CoV2, which later develop acute respiratory distress syndrome (ARDS), as a most common complication (50\%) requiring ICU and mechanical ventilation support and overall fatality rate of $64.7 \%[2,12]$. It is recommended that early diagnosis and prompt treatment is required to control high mortality due to COVID-19-associated pulmonary aspergillosis [5]. Although the mechanisms of COVID-19-associated aspergillosis susceptibility are not completely understood, virus-mediated increased IL-10 with Th2 immune response and decreased Th1 immune response 
was suggested to downregulate macrophage response and ultimate susceptibility to aspergillosis in COVID-19 patients $[12,13]$. Moreover, the role of SARS-CoV2-associated therapeutic regimens is also suggested in increasing IPA susceptibility among COVID-19 patients. For example, elevated IL-6 contributes to inflammation and resultant COVID-19 severity through cytokine release storm and its blockade is suggested to manage COVID-19 induced cytokine storm [14]. As IL-6 was suggested to provide protection against Aspergillus infection, its inhibition can also modulate the chances of IPA [15]. The use of steroids for the management of SARS-CoV2-associated inflammation is also suspected to be involved in increased IPA susceptibility through treatment-associated immunosuppression but needs more investigations [16, 17].

Due to increased importance of IPA in COVID-19 patients, it is necessary to explore the pathogenic mechanism of this disease combination. We performed system biologybased host-pathogen interaction analysis of SARS-CoV2 and A. fumigatus in order to find the interaction of both pathogens with aspergillosis targets. In addition, the role of these targets was explored to find the disease mechanisms and subsequent therapeutic targets.

\section{Methods}

\section{Database}

SARS-CoV2 and coronavirus-related HPI were downloaded from BIOGRID interaction database v. 4.4.197 (Last Modified: April 28th, 2021—05:13:54 AM EST). Aspergillus fumigatus (strain ATCC MYA-4609/Af293/CBS 101355/ FGSC A1100) (Neosartorya fumigata) reference proteome was downloaded from Uniprot (UP000002530). Human reference proteome with proteome ID UP000005640 (tax ID 9606) was also downloaded from Uniprot.

\section{Homology-based Host-Pathogen Interactions Detection}

As per the published literature survey, A. fumigatus is involved in majority of the cases of COVID-19-associated pulmonary aspergillosis (nearly $89.7 \%$ ) and therefore, its reference proteome was used to predict HPI with human proteome through homology modeling [12]. Homology modeling is a well-established method of protein-protein interaction detection which assumes that protein $\mathrm{X}$ and $\mathrm{Y}$ are interacting pair provided their homolog $\mathrm{X}$; and $\mathrm{Y}$; are already a known interacting pair. Previous studies have found that proteins with $30 \%$ sequence similarity can interact with each other [18]. Therefore, we predicted HPI with 30\% sequence identity and 1e-5 E-value through host-pathogen interaction database (HPIDB) [19] and BIANA interlog prediction server [20].

\section{Screening of Aspergillosis Targets}

Invasive aspergillosis targets were downloaded from DisGeNet (concept unique identifier, CUI: C0238013) and Genecards. The targets identified from both databases were combined and filtered for removal of redundant entries. The unique invasive aspergillosis targets were used for further analysis.

\section{Construction of HPI Maps and Identification of Aspergillosis Targets in HPI Map}

The host pathogen interaction maps of A. fumigatus and SARS-CoV2 were prepared through Cytoscape v 3.8.0 on the basis of HPI data obtained in earlier steps. The HPI involving aspergillosis targets were also identified in HPI maps for assessing the role of individual pathogen in aspergillosis pathogenesis and their subsequent involvement in COVID-19-associated aspergillosis susceptibility prediction.

\section{Construction of Comparative HPI Map and Functional Overrepresentation Analysis of Interacting Human Targets}

Due to a large number of interacting aspergillosis-specific human targets in HPI maps, we performed functional overrepresentation analysis of interacting target set to find overrepresented functions associated with both HPI. The interacting aspergillosis human targets were divided in three parts, first proteins interacting with SARS-CoV2, proteins predicted to interact with A. fumigatus, and aspergillosis targets interacting with both, SARS-CoV2 and A. fumigatus. PANTHER Overrepresentation Test (Released 20,210,224) with PANTHER version 16.0 Released 2020-12-01 was used to analyze overrepresented pathways and gene ontology: biological process (GO:BP). Fisher Direct test with false discovery rate (FDR) correction was used to understand the role of each target set in modulation of different processes related to aspergillosis.

\section{Results}

\section{Database}

BIOGRID database $\mathrm{v} 4.4 .197$ contains 22,324 coronavirusrelated HPI with literature evidences. These HPI includes SARS-, MERS-, and SARS-CoV2-related HPI with a variety of hosts. The details of HPI with different hosts are presented in Table 1. After filtering SARS-CoV2 related HPI 
Table 1 Details of hostpathogen interactions found in BIOGRID v 4.4.197 for coronavirus related interactions

\begin{tabular}{|c|c|c|c|}
\hline Interactor A & Interactor B & $\begin{array}{l}\text { Number of host-patho- } \\
\text { gen interactions }\end{array}$ & $\begin{array}{l}\text { Total number of } \\
\text { host-pathogen inter- } \\
\text { actions }\end{array}$ \\
\hline Cricetulus griseus & SARS-CoV & 1 & 1 \\
\hline \multirow[t]{3}{*}{ Homo sapiens } & MERS & 11 & 201 \\
\hline & SARS-CoV2 & 130 & \\
\hline & SARS-CoV & 60 & \\
\hline Mus musculus & SARS-CoV & 1 & 1 \\
\hline \multirow[t]{2}{*}{ MERS } & Homo sapiens & 337 & 340 \\
\hline & MERS & 3 & \\
\hline \multirow[t]{8}{*}{ SARS-CoV 2} & Canis familiaris & 1 & 20,228 \\
\hline & Felis Catus & 1 & \\
\hline & Homo sapiens & 19,912 & \\
\hline & Macaca mulatta & 1 & \\
\hline & Mus musculus & 2 & \\
\hline & Oryctolagus cuniculus & 1 & \\
\hline & SARS-CoV 2 & 308 & \\
\hline & SARS-CoV & 2 & \\
\hline \multirow[t]{3}{*}{ SARS-CoV } & Homo sapiens & 1279 & 1553 \\
\hline & SARS-CoV 2 & 5 & \\
\hline & SARS-CoV & 269 & \\
\hline Total HPI & & & 22,324 \\
\hline
\end{tabular}

from whole interaction dataset, a total of 20,042 HPI were found between 30 SARS-CoV2 proteins and 4736 human proteins. A total of 15,395 unique HPI were found after the removal of 4647 redundant HPI. Reference proteome of Neosartorya fumigata (A. fumigatus) contains 9,647 proteins, including 833 reviewed and 8,814 unreviewed proteins of fungi at the time of analysis. Reference human proteome included 20,380 reviewed and 56,647 unreviewed protein entries in UniprotKB at the time of analysis.

\section{Homology-based HPI Detection}

Homology-based HPI detection found total 308,004 HPI with BIANA interlog prediction server (BIPS), while 26,343 HPI with HPIDB. BIPS found 306,366 unique interactions while 16,383 unique HPI were found with HPIDB. After combining HPI data from both databases total 321,703 nonredundant HPI were found after the removal of 1046 redundant HPI located with both databases. These unique HPI included 2325 A. fumigatus proteins while 24,260 human proteins.

\section{Screening of Aspergillosis Targets}

While screening for invasive aspergillosis targets, DisGeNet found 81 targets and GeneCards found 240 disease targets at the time of target search. Total 321 aspergillosis targets obtained from both database were filtered to find 275 unique invasive aspergillosis targets after removal of 46 duplicate entries found in both database.

\section{Construction of HPI Maps and Identification of Interactions with Aspergillosis Targets}

HPI targets details and map of A. fumigatus and SARS$\mathrm{CoV} 2$ involved in interaction with aspergillosis targets are presented in Figs. 1 and 2, respectively. Figure 3 indicates about HPI with known aspergillosis targets. Table S1

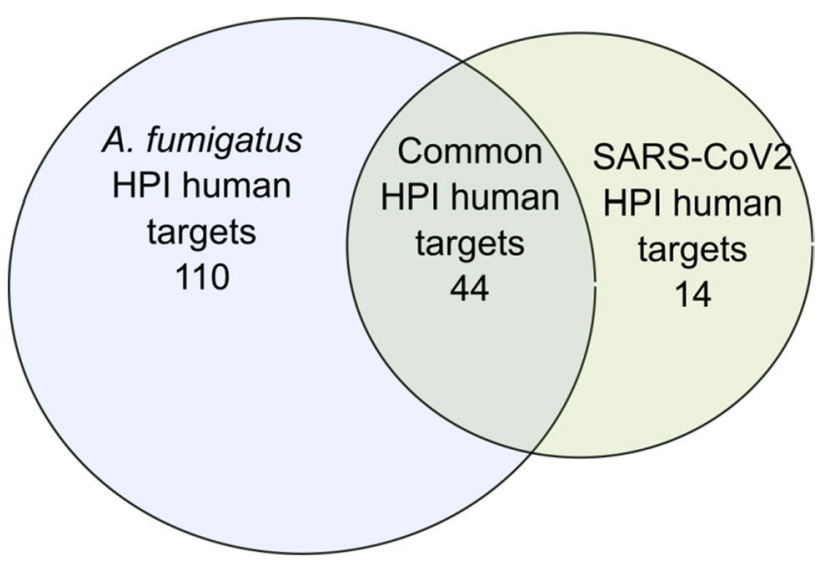

Fig. 1 Venn diagram indicating aspergillosis targets involved in HPI with both pathogens in addition to HPI with aspergillosis targets commonly involved in both interaction maps 
Fig. 2 The host-pathogen interaction map of $A$. fumigatus (A) and SARS-CoV2 (B) with human. The blue color nodes indicate pathogen proteins while host proteins are generally indicated through red color nodes, except human targets involved in aspergillosis which are shown by green color nodes

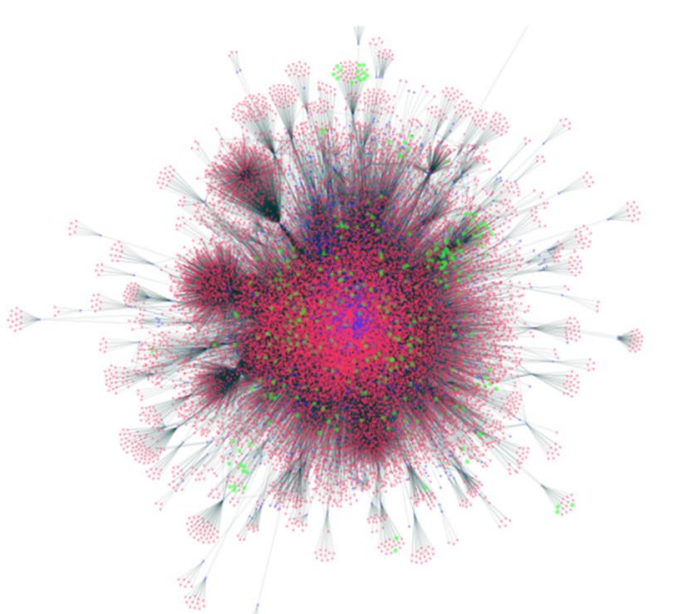

(A)

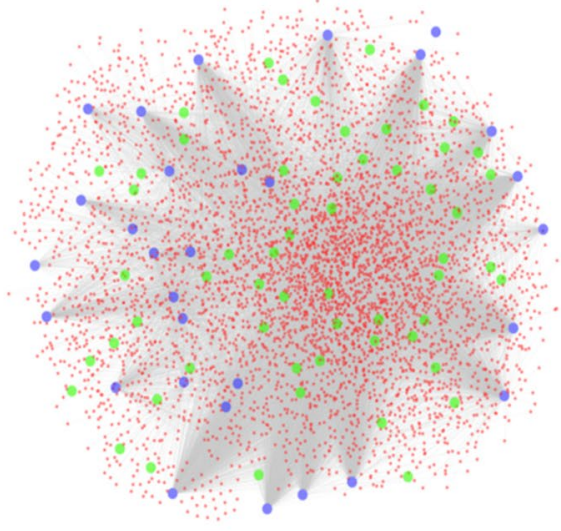

(B)

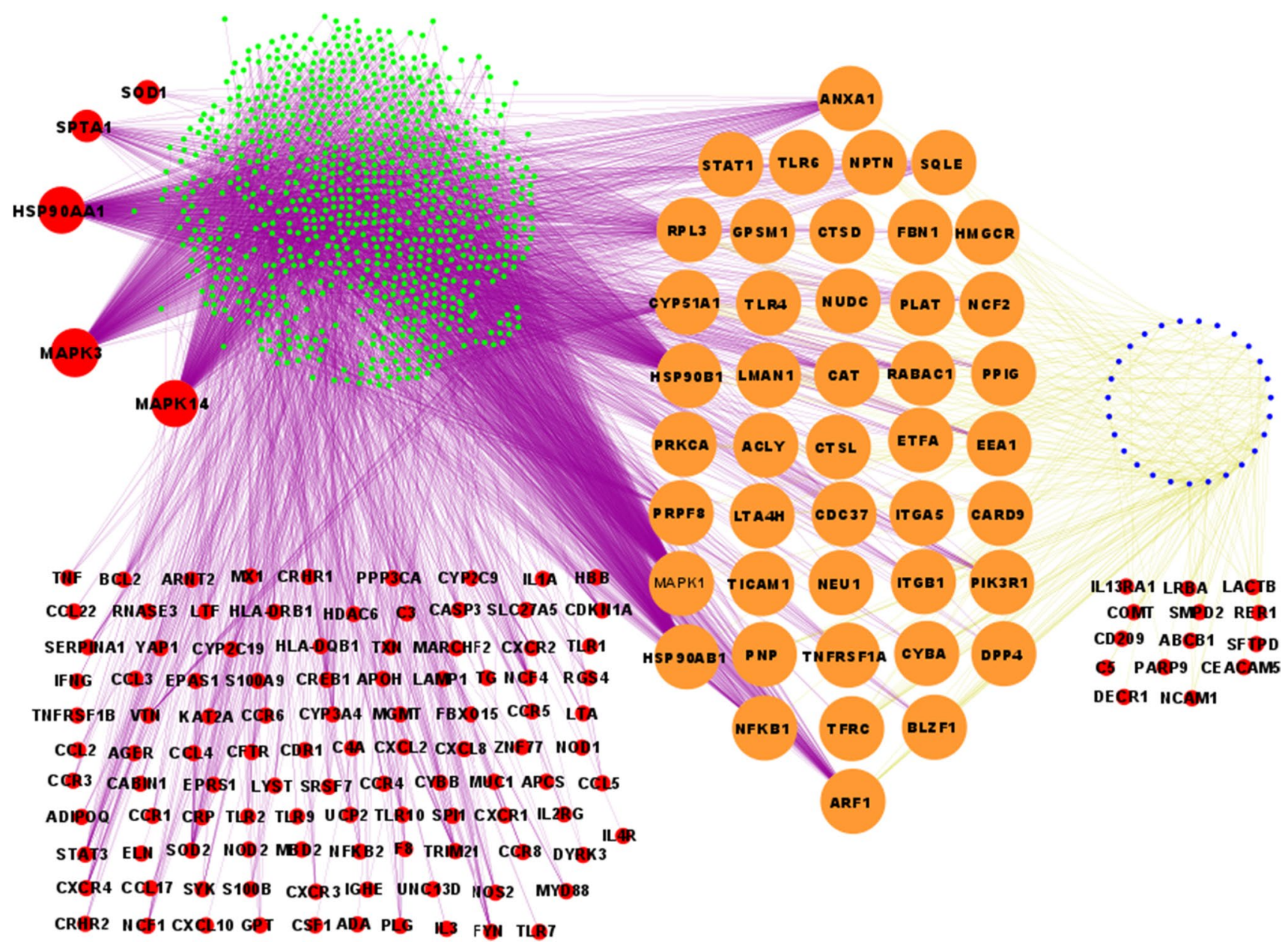

Fig. 3 Comparative host-pathogen interaction map of aspergillosis targets. The green color nodes indicate A. fumigatus proteins while blue color nodes indicate SARS-CoV2 proteins. Human targets are generally shown with red color except commonly interacting human targets, those are presented with orange, large size nodes. The top five human proteins exclusively predicted to interact with $A$. fumiga- tus are shown with large size nodes and arranged as per their degree value, which represents number of connecting edges with a particular target and therefore their central involvement in interaction network. Homology-based HPI were shown with purple edges while SARS$\mathrm{CoV} 2$ host-pathogen interactions according to BIOGRID are shown with orange edges 
indicates specific HPI of A. fumigatus and SARS-CoV2 with known aspergillosis targets predicted during our data analysis. Out of total SARS-CoV2 HPI, 216 HPI were found with aspergillosis targets involving 27 SARS-CoV2 and 58 human proteins interactions. Regarding A. fumigatus HPI, 3532 HPI were found with aspergillosis targets involving 861 A. fumigatus and 154 human targets.

\section{Comparative HPI Map and Functional Overrepresentation Analysis}

During construction of comparative HPI map, a total of 44 aspergillosis targets were found common between both A. fumigatus and SARS-CoV2 HPI maps. Figure 3 indicates comparative HPI map of both pathogens with aspergillosis targets. In addition, Fig. 4 indicates overrepresentation analysis for gene ontology: biological process and pathways using PANTHER database.

\section{Discussion}

Aspergillosis is an important cause of morbidity and mortality among immunocompromised individuals with a broad spectrum of diseases ranging from noninvasive to invasive, severe, and rapidly fatal infections $[21,22]$. The invasive aspergillosis is considered the most severe form of aspergillosis which is generally associated with aggressive immunosuppressive therapies for the management of certain condition [23]. The increased incidence of aspergillosis among COVID-19 patients is also alarming and possibly linked to immunosuppressive treatment used for management of inflammatory response $[24,25]$. The high incidence of invasive aspergillosis associated with COVID-19 patients created a big challenge among the scientific community [26], because of its poor prognosis even after advancement in current microbiological diagnosis and therapeutic interventions [27]. In addition to the role of immunosuppression, the SARS-CoV2 infection can also play diverse roles in increasing susceptibility to invasive aspergillosis. Therefore, it is necessary to understand the role of SARS-CoV2, in addition

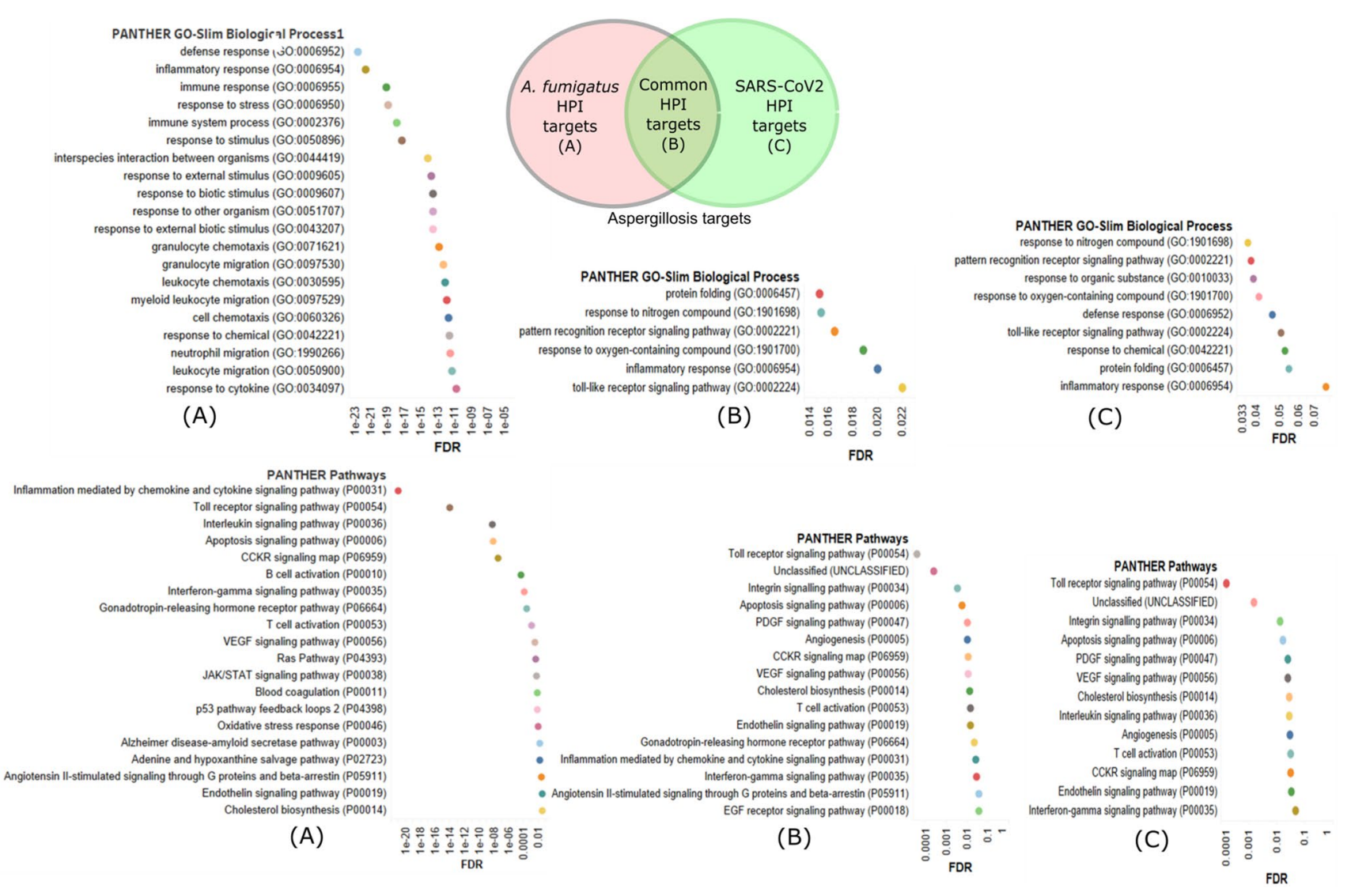

Fig. 4 Functional overrepresentation analysis of aspergillosis targets involved in HPI with A. fumigatus and SARS-CoV2. Only up to top 20 terms are shown in the figure 
to Aspergillus for increasing susceptibility to aspergillosis among COVID-19 patients.

Significant efforts of global scientific community made several breakthroughs in understanding molecular basis of SARS-CoV2 pathogenesis. A large number of studies have reported SARS-CoV2 interactions with several host targets and their subsequent contribution in pathogenesis [28]. These interactions have been compiled in several interaction databases. BIOGRID is a big curated database reporting several biological interactions. Its version 4.4.197 contains 2,045,743 raw interactions and 1,611,895 nonredundant interactions. This database hosts a separate project for listing coronavirus-related interactions, which includes 22,324 interactions at the time of study, and this number is continuously updated with the addition of new information provided by global scientific community [29]. These host-pathogen interactions are listed with relevant experimental and literature support for each interaction (Table 1). As these interactions are already supported with literature evidences, the quality of source data creates reliance on our predicted findings.

In contrast, due to relatively novel nature of this pandemic, limited information is available about co-infections and superinfections in COVID-19 patients, though this information is continuously emerging with several recent findings. Several routine studies are reporting microbiota modulation in COVID-19 patients in order to understand overrepresented microbes and their mechanistic implications [30-32], but the role of each microbe is not well understood except very few studies unraveling mechanistic implications of overrepresented bacteria in the severity of COVID-19 [33]. Despite this, complete mechanistic exploration of aspergillosis pathogenesis is not made yet and therefore data about role of host-pathogen interactions during aspergillosis is not readily available. This is the reason for our reliance on detection of A. fumigatus host-pathogen interactions through system biology-based homology modeling. Homology modeling predicts protein $\mathrm{X}$ and $\mathrm{Y}$ as interacting pair or inter$\operatorname{logs}$, if their homologs $\mathrm{X}$ : and $\mathrm{Y}$ : are already known to interact with each other. We predicted these interlogs between $A$. fumigatus and human through prediction server of Biologic Interaction And Network Analysis (BIANA) database [20, 34] and Host-Pathogen Interaction DataBase (HPIDB) v. 3.0 [19]. The detection of host-pathogen interactions through homology modeling is considered an important method which has been used in several studies [33, 35, 36]. Homology modeling detects homologous interacting pairs in a number of interaction databases and this makes it superior than searching simple homology. BIANA detects homology of query proteins with known interacting pairs in several interaction databases, such as DIP, IntAt, MINT, Mpact, PHI_base, PIG, BIND, BIOGRID, and VirusMINT. BIANA provides $72-98 \%$ sensitivity and up to $59 \%$ specificity for interaction detection with different homology conditions [20]. Moreover, HPIDB is also a well-known database with 69,787 curated unique interactions involving 668 pathogen and 66 host species [19]. The redundant host-pathogen interactions predicted through HPIDB and BIANA were filtered to find unique interactions which we assume to provide highquality host-pathogen interaction data for most common COVID-19-associated aspergillosis pathogen A. fumigatus and human. The human targets involved in invasive aspergillosis were also screened through GeneCards and DisGeNet, which are well-known databases listing disease targets with relevant literature or experimental support [37, 38].

The findings of this study indicate that SARS-CoV2 can recruit several additional aspergillosis targets in addition to targets recruited by actual etiologic agent, i.e., $A$. fumigatus (Fig. 1) and therefore, it can also contribute to the development of invasive aspergillosis. Consequently, COVID-19 infection itself may be involved in increasing susceptibility to aspergillosis and therefore, immunosuppressive therapy cannot be solely blamed. Out of a total of 30 SARS-CoV2 proteins present in HPI in BIOGRID, 27 were found to interact with certain aspergillosis targets and this indicates an important contribution of SARS-CoV2 in modulating aspergillosis susceptibility among patients (Figs. 2 and 3). Figure 3 lists 44 human aspergillosis targets commonly interacting with SARS-CoV2 and A. fumigatus. These targets can have a variety of consequences on disease progression. Annexin A1 (ANXA1) is one of such targets, which has been proposed as a biomarker for IPA and its mimic is proposed as a therapeutic option for COVID-19 by controlling inflammatory response [39, 40]. TLR6 and TLR4 are also aspergillosis targets commonly involved in SARS-CoV2 and A. fumigatus HPI maps (Fig. 3) and the role of TLR is already known in recognition of pathogens. It is known that $A$. fumigatus modulate proinflammatory response through host TLR2 and TLR4 signaling and resultant IL-6 production [41]. Figure 3 clearly indicates HPI of A. fumigatus with both aspergillosis regulators (TLR2 and TLR6) giving support to our prediction method as well as role of SARS-CoV2 in aspergillosis. The role of TLR4 is discussed in the severity of COVID-19 through IL-6 [42], collective involvement of these TLR in pathogenesis of multiple pathogens needs separate investigation to understand their role during IPA in COVID-19 patients. The role of IL-1 is also evidenced in COVID-19 due to production of IL- $1 \alpha$ in response to epithelial damage and production of IL-1ß through NLRP3 inflammasome. Targeting of NLRP3/IL-1 pathway through recombinant IL-1 receptor antagonist anakinra was found beneficial in COVID-19 patients. The IL- $1 \alpha$ is found in homology-based A. fumigatus HPI and anakinra is found to protect against aspergillosis [43]. Therefore, role of such aspergillosis regulators which are already known in 
preventing COVID-19-associated severity deserved a separate study and current data analysis can help for designing the same. Similarly, common involvement of NF-kB in both HPI is further supported by discrete studies suggesting targeting of NF-kB pathway for management of both, COVID-19 and aspergillosis $[44,45]$. The role of STAT1 is also discussed in modulating antiviral immunity through A. fumigatus extract, but the exact role of this relation in modulating aspergillosis susceptibility among COVID19 patients needs separate investigations [46]. Several other inflammatory regulators are commonly interacting with both pathogens and can alter the fate of aspergillosis development among COVID-19 patients (Fig. 3).

The above findings are also evidenced through functional overrepresentation analysis of aspergillosis target (Fig. 4). The common targets are involved in pattern recognition receptor signaling and inflammatory response as evidenced through functional overrepresentation analysis against gene ontology: biological process using PANTHER overrepresentation tool. In addition, SARS-CoV2associated interactors are involved in regulation of TLR, integrin, apoptosis, PDGF, VEGF, etc. pathways. Some of these pathways were also found to be enriched in some different studies related to aspergillosis [47, 48]. The modulation of several aspergillosis-associated pathways through SARS-CoV2-associated HPI and common interactions with aspergillosis targets indicate that this data can be used to design management strategies to mitigate or treat aspergillosis in COVID-19 patients.

The use of system biology-based host-pathogen interaction analysis is adding value in understanding several diseases $[49,50]$ and the results obtained in the current study indicate several caveats for invasive aspergillosis pathogenesis in COVID-19 patients, but the computational approaches are also associated with certain limitations like other scientific methods [51]. We must consider that the current study is based on existing information available in a number of databases, but this information is not complete and continuously updating with the addition of new findings. This fact is also evident with detection of aspergillosis targets in relevant disease target databases which are not complete. Moreover, the detection of homology-based protein-protein interactions also depends on detection of homologous interlogs in relevant interaction databases. These interaction databases are also updating and not all the homologous protein-protein interactions are known. Therefore, it is important to consider these limitations while evaluating the data and the results must be correlated experimentally. Nevertheless, the findings are based on huge size of data generated in a large number of studies and therefore the results are of importance to find mechanistic implications of COVID-19-associated aspergillosis susceptibility and can be useful to tackle this infectious challenge associated with current pandemic.
Supplementary Information The online version contains supplementary material available at https://doi.org/10.1007/s00248-021-01913-6.

Author Contribution AAK: concept, experimental analysis, data interpretation, writing, editing, and approval of the final manuscript, FF: experimental analysis, editing, and approval of the final manuscript, SKJ: experimental analysis, data interpretation, editing, and approval of the final manuscript, PG: data interpretation, editing, and approval of the final manuscript, MR: data interpretation, editing, and approval of the final manuscript.

Availability of Data Data related to manuscript is either available as supplementary material or with relevant open access database.

\section{Declarations}

Ethics Approval and Consent to Participate Not applicable.

Competing Interest The authors declare no competing interests.

\section{References}

1. Zhu X, Ge Y, Wu T, Zhao K, Chen Y, Wu B, Zhu F, Zhu B, Cui L (2020) Co-infection with respiratory pathogens among COVID2019 cases. Virus Res 285:198005. https://doi.org/10.1016/j.virus res.2020.198005

2. Wang J, Yang Q, Zhang P, Sheng J, Zhou J, Qu T (2020) Clinical characteristics of invasive pulmonary aspergillosis in patients with COVID-19 in Zhejiang, China: a retrospective case series. Crit Care 24:299. https://doi.org/10.1186/s13054-020-03046-7

3. Alanio A, Delliere S, Fodil S, Bretagne S, Megarbane B (2020) Prevalence of putative invasive pulmonary aspergillosis in critically ill patients with COVID-19. Lancet Respir Med 8:e48-e49. https://doi.org/10.1016/S2213-2600(20)30237-X

4. Rutsaert L, Steinfort N, Van Hunsel T, Bomans P, Naesens R, Mertes H, Dits H, Van Regenmortel N (2020) COVID-19-associated invasive pulmonary aspergillosis. Ann Intensive Care 10:71. https://doi.org/10.1186/s13613-020-00686-4

5. van Arkel ALE, Rijpstra TA, Belderbos HNA, van Wijngaarden P, Verweij PE, Bentvelsen RG (2020) COVID-19-associated pulmonary aspergillosis. Am J Respir Crit Care Med 202:132-135. https://doi.org/10.1164/rccm.202004-1038LE

6. Koehler P, Cornely OA, Bottiger BW, Dusse F, Eichenauer DA, Fuchs F, Hallek M, Jung N, Klein F, Persigehl T, Rybniker J, Kochanek M, Boll B, Shimabukuro-Vornhagen A (2020) COVID19 associated pulmonary aspergillosis. Mycoses 63:528-534. https://doi.org/10.1111/myc.13096

7. Blaize M, Mayaux J, Nabet C, Lampros A, Marcelin AG, Thellier M, Piarroux R, Demoule A, Fekkar A (2020) Fatal invasive aspergillosis and coronavirus disease in an immunocompetent patient. Emerg Infect Dis 26:1636-1637. https://doi.org/10.3201/eid2607. 201603

8. Antinori S, Rech R, Galimberti L, Castelli A, Angeli E, Fossali T, Bernasconi D, Covizzi A, Bonazzetti C, Torre A, Carsana L, Tonello C, Zerbi P, Nebuloni M (2020) Invasive pulmonary aspergillosis complicating SARS-CoV-2 pneumonia: a diagnostic challenge. Travel Med Infect Dis 38:101752. https://doi.org/10.1016/j. tmaid.2020.101752

9. Prattes J, Valentin T, Hoenigl M, Talakic E, Reisinger AC, Eller P (2021) Invasive pulmonary aspergillosis complicating COVID-19 in the ICU - a case report. Med Mycol Case Rep 31:2-5. https:// doi.org/10.1016/j.mmcr.2020.05.001 
10. Mitaka H, Perlman DC, Javaid W, Salomon N (2020) Putative invasive pulmonary aspergillosis in critically ill patients with COVID-19: an observational study from New York City. Mycoses 63:1368-1372. https://doi.org/10.1111/myc.13185

11. Blot S, Rello J, Koulenti D (2019) Diagnosing invasive pulmonary aspergillosis in ICU patients: putting the puzzle together. Curr Opin Crit Care 25:430-437. https://doi.org/10.1097/MCC.00000 00000000637

12. Lai CC, Yu WL (2021) COVID-19 associated with pulmonary aspergillosis: a literature review. J Microbiol Immunol Infect 54:46-53. https://doi.org/10.1016/j.jmii.2020.09.004

13. Del Sero G, Mencacci A, Cenci E, d'Ostiani CF, Montagnoli C, Bacci A, Mosci P, Kopf M, Romani L (1999) Antifungal type 1 responses are upregulated in IL-10-deficient mice. Microbes Infect 1:1169-1180. https://doi.org/10.1016/s1286-4579(99) 00245-2

14. Liu B, Li M, Zhou Z, Guan X, Xiang Y (2020) Can we use interleukin-6 (IL-6) blockade for coronavirus disease 2019 (COVID19)-induced cytokine release syndrome (CRS)? J Autoimmun 111:102452. https://doi.org/10.1016/j.jaut.2020.102452

15. Su H, Li C, Wang Y, Li Y, Dong L, Li L, Zhu J, Zhang Q, Liu G, $\mathrm{Xu}$ J, Zhu M (2019) Kinetic host defense of the mice infected with Aspergillus fumigatus. Future Microbiol 14:705-716. https://doi. org/10.2217/fmb-2019-0043

16. Wang H, Ding Y, Li X, Yang L, Zhang W, Kang W (2003) Fatal aspergillosis in a patient with SARS who was treated with corticosteroids. N Engl J Med 349:507-508. https://doi.org/10.1056/ NEJM200307313490519

17. Armstrong-James D, Youngs J, Bicanic T, Abdolrasouli A, Denning DW, Johnson E, Mehra V, Pagliuca T, Patel B, Rhodes J, Schelenz S, Shah A, van de Veerdonk FL, Verweij PE, White PL, Fisher MC (2020) Confronting and mitigating the risk of COVID19 associated pulmonary aspergillosis. Eur Respir J 56:2002554. https://doi.org/10.1183/13993003.02554-2020

18. Espadaler J, Romero-Isart O, Jackson RM, Oliva B (2005) Prediction of protein-protein interactions using distant conservation of sequence patterns and structure relationships. Bioinformatics 21:3360-3368. https://doi.org/10.1093/bioinformatics/bti522

19. Ammari MG, Gresham CR, McCarthy FM, Nanduri B (2016) HPIDB 2.0: a curated database for host-pathogen interactions. Database 2016. https://doi.org/10.1093/database/baw103

20. Garcia-Garcia J, Schleker S, Klein-Seetharaman J, Oliva B (2012) BIPS: BIANA Interolog Prediction Server. A tool for proteinprotein interaction inference. Nucleic Acids Res 40:W147-151. https://doi.org/10.1093/nar/gks553

21. Cadena J, Thompson GR 3rd, Patterson TF (2016) Invasive aspergillosis: current strategies for diagnosis and management. Infect Dis Clin North Am 30:125-142. https://doi.org/10.1016/j.idc. 2015.10.015

22. Salmanton-Garcia J, Sprute R, Stemler J, Bartoletti M, Dupont D, Valerio M, Garcia-Vidal C, Falces-Romero I, Machado M, de la Villa S, Schroeder M, Hoyo I, Hanses F, Ferreira-Paim K, Giacobbe DR, Meis JF, Gangneux JP, Rodriguez-Guardado A, Antinori S, Sal E, Malaj X, Seidel D, Cornely OA, Koehler P, FungiScope European Confederation of Medical Mycology/The International Society for H, Animal Mycology Working G (2021) COVID-19-associated pulmonary aspergillosis, March-August 2020. Emerg Infecti Dis 27:1077-1086. https://doi.org/10.3201/ eid2704.204895

23. Darling BA, Milder EA (2018) Invasive aspergillosis. Pediatr Rev 39:476-478. https://doi.org/10.1542/pir.2017-0129

24. Machado M, Valerio M, Alvarez-Uria A, Olmedo M, Veintimilla C, Padilla B, De la Villa S, Guinea J, Escribano P, Ruiz-Serrano MJ, Reigadas E, Alonso R, Guerrero JE, Hortal J, Bouza E, Munoz P, Group C-S (2021) Invasive pulmonary aspergillosis in the COVID-19 era: an expected new entity. Mycoses 64:132-143. https://doi.org/10.1111/myc.13213

25. Trujillo H, Fernandez-Ruiz M, Gutierrez E, Sevillano A, Caravaca-Fontan F, Morales E, Lopez-Medrano F, Aguado JM, Praga M, Andres A (2021) Invasive pulmonary aspergillosis associated with COVID-19 in a kidney transplant recipient. Transplant Infect Dis 23:e13501. https://doi.org/10.1111/tid.13501

26. Bartoletti M, Pascale R, Cricca M, Rinaldi M, Maccaro A, Bussini L, Fornaro G, Tonetti T, Pizzilli G, Francalanci E, Giuntoli L, Rubin A, Moroni A, Ambretti S, Trapani F, Vatamanu O, Ranieri VM, Castelli A, Baiocchi M, Lewis R, Giannella M, Viale P, group Ps (2020) Epidemiology of invasive pulmonary aspergillosis among COVID-19 intubated patients: a prospective study. Clin Infect Dis. https://doi.org/10.1093/cid/ciaa1065

27. Blanchard E, Gabriel F, Jeanne-Leroyer C, Servant V, Dumas PY (2018) Invasive pulmonary aspergillosis. Rev Mal Respir 35:171187. https://doi.org/10.1016/j.rmr.2018.01.002

28. Khan AA, Khan Z (2021) Comparative host-pathogen proteinprotein interaction analysis of recent coronavirus outbreaks and important host targets identification. Brief Bioinform 22:12061214. https://doi.org/10.1093/bib/bbaa207

29. Oughtred R, Rust J, Chang C, Breitkreutz BJ, Stark C, Willems A, Boucher L, Leung G, Kolas N, Zhang F, Dolma S, CoulombeHuntington J, Chatr-Aryamontri A, Dolinski K, Tyers M (2021) The BioGRID database: a comprehensive biomedical resource of curated protein, genetic, and chemical interactions. Protein Sci 30:187-200. https://doi.org/10.1002/pro.3978

30. Zuo T, Zhang F, Lui GCY, Yeoh YK, Li AYL, Zhan H, Wan Y, Chung ACK, Cheung CP, Chen N, Lai CKC, Chen Z, Tso EYK, Fung KSC, Chan V, Ling L, Joynt G, Hui DSC, Chan FKL, Chan PKS, Ng SC (2020) Alterations in gut microbiota of patients with COVID-19 during time of hospitalization. Gastroenterology 159(944-955):e948. https://doi.org/10.1053/j.gastro.2020.05.048

31. Yeoh YK, Zuo T, Lui GC, Zhang F, Liu Q, Li AY, Chung AC, Cheung CP, Tso EY, Fung KS, Chan V, Ling L, Joynt G, Hui DS, Chow KM, Ng SSS, Li TC, Ng RW, Yip TC, Wong GL, Chan FK, Wong CK, Chan PK, Ng SC (2021) Gut microbiota composition reflects disease severity and dysfunctional immune responses in patients with COVID-19. Gut 70:698-706. https://doi.org/10. 1136/gutjnl-2020-323020

32. Khan AA, Singh H, Bilal M, Ashraf MT (2021) Microbiota, probiotics and respiratory infections: the three muskateers can tip off potential management of COVID-19. Am J Trans Res 13(10):10977-10993

33. Khan AA, Khan Z (2020) COVID-2019-associated overexpressed Prevotella proteins mediated host-pathogen interactions and their role in coronavirus outbreak. Bioinformatics 36:4065-4069. https://doi.org/10.1093/bioinformatics/btaa285

34. Garcia-Garcia J, Guney E, Aragues R, Planas-Iglesias J, Oliva B (2010) Biana: a software framework for compiling biological interactions and analyzing networks. BMC Bioinformatics 11:56. https://doi.org/10.1186/1471-2105-11-56

35 Khan AA, Abuderman AA, Ashraf MT, Khan Z (2020) Proteinprotein interactions of HPV-Chlamydia trachomatis-human and their potential in cervical cancer. Futur Microbiol 15:509-520. https://doi.org/10.2217/fmb-2019-0242

36. Huo T, Liu W, Guo Y, Yang C, Lin J, Rao Z (2015) Prediction of host - pathogen protein interactions between Mycobacterium tuberculosis and Homo sapiens using sequence motifs. BMC Bioinformatics 16:100. https://doi.org/10.1186/s12859-015-0535-y

37. Stelzer G, Rosen N, Plaschkes I, Zimmerman S, Twik M, Fishilevich S, Stein TI, Nudel R, Lieder I, Mazor Y, Kaplan S, Dahary D, Warshawsky D, Guan-Golan Y, Kohn A, Rappaport N, Safran M, Lancet D (2016) The GeneCards suite: from gene data mining 
to disease genome sequence analyses. Current Protocols in Bioinformatics 54:1.30.1-1.30.33. https://doi.org/10.1002/cpbi.5

38. Pinero J, Bravo A, Queralt-Rosinach N, Gutierrez-Sacristan A, Deu-Pons J, Centeno E, Garcia-Garcia J, Sanz F, Furlong LI (2017) DisGeNET: a comprehensive platform integrating information on human disease-associated genes and variants. Nucleic Acids Res 45:D833-D839. https://doi.org/10.1093/nar/gkw943

39. Bonavita AG (2020) Ac2-26 mimetic peptide of annexin A1 to treat severe COVID-19: a hypothesis. Med Hypotheses 145:110352. https://doi.org/10.1016/j.mehy.2020.110352

40. Krel M, Petraitis V, Petraitiene R, Jain MR, Zhao Y, Li H, Walsh TJ, Perlin DS (2014) Host biomarkers of invasive pulmonary aspergillosis to monitor therapeutic response. Antimicrob Agents Chemother 58:3373-3378. https://doi.org/10.1128/AAC. 02482-14

41. Chai LYA, Vonk AG, Kullberg BJ, Verweij PE, Verschueren I, van der Meer JWM, Joosten LAB, Latgé J-P, Netea MG (2011) Aspergillus fumigatus cell wall components differentially modulate host TLR2 and TLR4 responses. Microbes Infect 13:151-159. https:// doi.org/10.1016/j.micinf.2010.10.005

42 Brandao SCS, Ramos JOX, Dompieri LT, Godoi E, Figueiredo JL, Sarinho ESC, Chelvanambi S, Aikawa M (2021) Is Toll-like receptor 4 involved in the severity of COVID-19 pathology in patients with cardiometabolic comorbidities? Cytokine Growth Fact Rev 58:102-110. https://doi.org/10.1016/j.cytogfr.2020.09. 002

43. Costantini C, van de Veerdonk FL, Romani L (2020) Covid19-associated pulmonary aspergillosis: the other side of the coin. Vaccines 8. https://doi.org/10.3390/vaccines8040713

44. Kircheis R, Haasbach E, Lueftenegger D, Heyken WT, Ocker M,

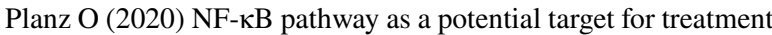
of critical stage COVID-19 patients. Front Immunol 11. https:// doi.org/10.3389/fimmu.2020.598444
45. Panackal AA, Bennett JE, Williamson PR (2014) Treatment options in invasive aspergillosis. Curr Treat Options Infect Dis 6:309-325. https://doi.org/10.1007/s40506-014-0016-2

46. Bhushan B, Homma T, Norton JE, Sha Q, Siebert J, Gupta DS, Schroeder JW Jr, Schleimer RP (2015) Suppression of epithelial signal transducer and activator of transcription 1 activation by extracts of Aspergillus fumigatus. Am J Respir Cell Mol Biol 53:87-95. https://doi.org/10.1165/rcmb.2014-0333OC

47. Desoubeaux G, Chauvin D, Piqueras MDC, Bronson E, Bhattacharya SK, Sirpenski G, Bailly E, Cray C (2018) Translational proteomic study to address host protein changes during aspergillosis. PLoS ONE 13:e0200843. https://doi.org/10.1371/journal. pone. 0200843

48. Liu H, Lee MJ, Solis NV, Phan QT, Swidergall M, Ralph B, Ibrahim AS, Sheppard DC, Filler SG (2016) Aspergillus fumigatus CalA binds to integrin alpha5beta1 and mediates host cell invasion. Nat Microbiol 2:16211. https://doi.org/10.1038/nmicrobiol. 2016.211

49 Khan AA, Bano Y (2021) Salmonella enterica subsp. enterica host-pathogen interactions and their implications in gallbladder cancer. Microbial Pathog 157:105011. https://doi.org/10.1016/j. micpath.2021.105011

50. Khan AA, Khan Z, Malik A, Shrivastava A, Jain SK, Alshamsan A (2015) Computational prediction of Escherichia coli proteins host subcellular targeting and their implications in colorectal cancer etiology. Cancer Lett 364:25-32. https://doi.org/10.1016/j. canlet.2015.04.024

51. Khan AA, Khan Z, Kalam MA, Khan AA (2018) Inter-kingdom prediction certainty evaluation of protein subcellular localization tools: microbial pathogenesis approach for deciphering host microbe interaction. Brief Bioinform 19:12-22. https://doi.org/ 10.1093/bib/bbw093 